\title{
The role of well-defined nanotopography of titanium implants on osseointegration: cellular and molecular events in vivo
}

This article was published in the following Dove Press journal:

International Journal of Nanomedicine

I April 2016

Number of times this article has been viewed

\section{Dimitrios Karazisis ${ }^{1-3}$ \\ Ahmed M Ballo, 1,2,4 \\ Sarunas Petronis ${ }^{2,5}$ \\ Hossein Agheli ${ }^{1,2}$ \\ Lena Emanuelsson ${ }^{1,2}$ \\ Peter Thomsen ${ }^{1,2}$ \\ Omar Omar ${ }^{1,2}$}

'Department of Biomaterials, Institute of Clinical Sciences, Sahlgrenska

Academy, University of Gothenburg, Gothenburg, Sweden; ${ }^{2}$ BIOMATCELL, VINN Excellence Center of Biomaterials and Cell Therapy, Gothenburg, Sweden; ${ }^{3}$ Department of Oral and Maxillofacial Surgery, Sahlgrenska Academy, University of Gothenburg, Sweden; ${ }^{4}$ Department of Oral Health Sciences, Faculty of Dentistry, University of British Columbia, Vancouver, BC, Canada; ${ }^{5}$ Department of Chemistry, Materials and Surfaces, SP Technical Research Institute of Sweden, Borås, Sweden

\section{Correspondence: Omar Omar}

Department of Biomaterials, Institute of Clinical Sciences, Sahlgrenska Academy,

University of Gothenburg, Box 4I2,

SE-405 30 Gothenburg, Sweden

Tel +46 31 786295 I

Fax +46 3I 786294

Email omar.omar@biomaterials.gu.se
Purpose: Mechanisms governing the cellular interactions with well-defined nanotopography are not well described in vivo. This is partly due to the difficulty in isolating a particular effect of nanotopography from other surface properties. This study employed colloidal lithography for nanofabrication on titanium implants in combination with an in vivo sampling procedure and different analytical techniques. The aim was to elucidate the effect of well-defined nanotopography on the molecular, cellular, and structural events of osseointegration.

Materials and methods: Titanium implants were nanopatterned (Nano) with semispherical protrusions using colloidal lithography. Implants, with and without nanotopography, were implanted in rat tibia and retrieved after 3, 6, and 28 days. Retrieved implants were evaluated using quantitative polymerase chain reaction, histology, immunohistochemistry, and energy dispersive X-ray spectroscopy (EDS).

Results: Surface characterization showed that the nanotopography was well defined in terms of shape (semispherical), size ( $79 \pm 6 \mathrm{~nm})$, and distribution $\left(31 \pm 2\right.$ particles $\left./ \mu \mathrm{m}^{2}\right)$. EDS showed similar levels of titanium, oxygen, and carbon for test and control implants, confirming similar chemistry. The molecular analysis of the retrieved implants revealed that the expression levels of the inflammatory cytokine, $T N F-\alpha$, and the osteoclastic marker, CatK, were reduced in cells adherent to the Nano implants. This was consistent with the observation of less CD163-positive macrophages in the tissue surrounding the Nano implant. Furthermore, periostin immunostaining was frequently detected around the Nano implant, indicating higher osteogenic activity. This was supported by the EDS analysis of the retrieved implants showing higher content of calcium and phosphate on the Nano implants.

Conclusion: The results show that Nano implants elicit less periimplant macrophage infiltration and downregulate the early expression of inflammatory $(T N F-\alpha)$ and osteoclastic $(C a t K)$ genes. Immunostaining and elemental analyses show higher osteogenic activity at the Nano implant. It is concluded that an implant with the present range of well-defined nanocues attenuates the inflammatory response while enhancing mineralization during osseointegration.

Keywords: nanofabrication, gene expression, immunohistochemistry, energy dispersive X-ray spectroscopy, inflammatory cytokines, bone formation

\section{Introduction}

Osseointegration is a complex phenomenon and a prerequisite for the clinical success of bone-anchored dental and orthopedic implants. ${ }^{1}$ Experimental studies provide evidence that bone formation could be promoted by implant surface modifications, largely dependent on the alterations of surface topography and roughness. ${ }^{2}$ While it is established that surface roughness at the microscale plays influential roles for tissue healing and implant fixation, ${ }^{3,4}$ the role of surface topography at the nanoscale has BY NC and incorporate the Creative Commons Attribution - Non Commercial (unported, v3.0) License (http://creativecommons.org/licenses/by-nd/3.0/). By accessing the work you
hereby accept the Terms. Non-commercial uses of the work are permitted without any further permission from Dove Medical Press Limited, provided the work is properly attributed. For permission hereby accept the Terms. Non-commercial uses of the work are permitted without any further permission from Dove Medich
for commercial use of this work, please see paragraphs 4.2 and 5 of our Terms (https://www.dovepress.com/terms.php). 
not yet been explored in a systematic manner. In vivo studies have shown that implants with combined nanoscale and microscale roughness enhance the long-term bone response ${ }^{2}$ and promote bone-bonding and interface strength. ${ }^{5-7}$ However, conclusive understanding of the molecular mechanisms underlying the cell and tissue interactions with nanoscale topography, per se, is still lacking. This is, in part, due to the difficulty in isolating particular effects of nanotopography from other surface properties (eg, microtopography and surface chemistry). Moreover, most of the modification techniques produce nanotopographies with mixed nanofeature sizes, shapes, and distributions, hindering definite conclusion on which nanotopography parameters are of importance for osseointegration.

A major challenge is to create a predetermined nanotopography on titanium implants with complex three-dimensional (3D) geometries for in vivo studies. Previously, colloidal lithography has been employed to fabricate controlled and well-defined topographic or chemical nanopatterns on flat model surfaces intended for in vitro studies of biological effects induced by nanoscale surface features. ${ }^{8,9}$ This nanopatterning technique also provided model surfaces with similar microtopography and chemistry but systematically varied nanotopography parameters such as size and distribution density of nanofeatures. ${ }^{8-10}$ Recently, colloidal lithography has also been applied to nanopattern cylindrical model implants. ${ }^{11}$ Such model implants demonstrated higher bone-to-implant contact in vivo, with $60 \mathrm{~nm}$ semispherical protrusions compared to control nonpatterned implants and implants patterned with 120 and $220 \mathrm{~nm}$ semispherical protrusions, suggesting that bone formation is dependent on the size of the nanofeatures. ${ }^{11}$ However, the question remains on how such specific nanotopography is interpreted in vivo by cells in the implant microenvironment, and how that information is subsequently translated into biological processes, ultimately resulting in an improved osseointegration.

A platform combining molecular, morphological, and ultrastructural analytical techniques with an in vivo model has been successfully employed to study the complex cellular and molecular events during bone healing and osseointegration at microrough oxidized titanium implants. ${ }^{5,12-14}$ These studies have shown that the triggering effects of the surface properties are largely detected in the cells adherent to the implant. ${ }^{5,14}$ For instance, a downregulation of proinflammatory cytokines and upregulation of osteogenic and bone remodeling genes has been demonstrated for cells adherent to oxidized implants in comparison to machined (Ma) implants. ${ }^{5,14}$ This molecular cascade resulted in a higher level of bone in contact with the oxidized implant. ${ }^{5}$ Therefore, such a platform provides the possibility of highlighting the role of well-defined nanotopography on the biological processes of osseointegration.

On the basis of previous findings showing favored bone response to specific nanotopography, ${ }^{11}$ this study aimed at determining the effect of such nanotopography on the cellular and molecular events of osseointegration. The study employed a sampling procedure ${ }^{5,12-14}$ in combination with molecular, morphological, and structural analyses. The molecular analysis targeted selected genes involved in inflammation, bone formation, and resorption, whereas the latter analyses evaluated cells and bone tissues in association with the implant.

\section{Materials and methods Preparation of the model implants}

Eighty-four Ma implants made of commercially pure (grade II) titanium were used. The implants (Figure 1A and D) had threads only at the top $(2.0 \mathrm{~mm}$ in diameter, $0.5 \mathrm{~mm}$ in length), for engaging the cortical bone and ensuring primary stability after installation. The part of the implant to face the bone marrow was designed as a cylinder (1.8 $\mathrm{mm}$ in diameter and $1.5 \mathrm{~mm}$ in length). The implants were divided into two equal groups based on the topography of the cylindrical part. The test group was patterned with semispherical nanoprotrusions, while the control group was not patterned. Thereafter, both test and control groups were coated with titanium thin film in order to unify the chemistry of all implants.

Nanopatterning was performed by colloidal lithography as previously described. ${ }^{8,10}$ In order to form a sufficient positive surface charge on the implant surfaces, they were exposed to oxygen plasma (PlasmaTherm Batchtop V II RIE/PE, 250 W, 250 mTorr, 2 minutes; Plasma-Therm Inc., St Petersburg, FL, USA), soaked in 5\% wt/wt aluminum chloride hydroxide (Chlorohydrol; Summit Reheis, Huguenot, NY, USA) solution for 2 minutes, rinsed in Milli-Q water (Millipore Corporation, Billerica, MA, USA) and blow-dried with nitrogen. Then, the positively charged implants were soaked in a $2 \% \mathrm{wt} / \mathrm{wt}$ colloidal solution of negatively charged spherical nanoparticles (60 nm nominal diameter, surfactant free white polystyrene latex; Invitrogen Corp, Carsbab, CA, USA), so that the particles could self-assemble on the implant surface due to electrostatic interactions. Nonadsorbed nanoparticles were washed away by extensive rinsing in Milli-Q water (Millipore Corporation). The adsorbed polymeric nanoparticles were further fixed to the surface by increasing their 

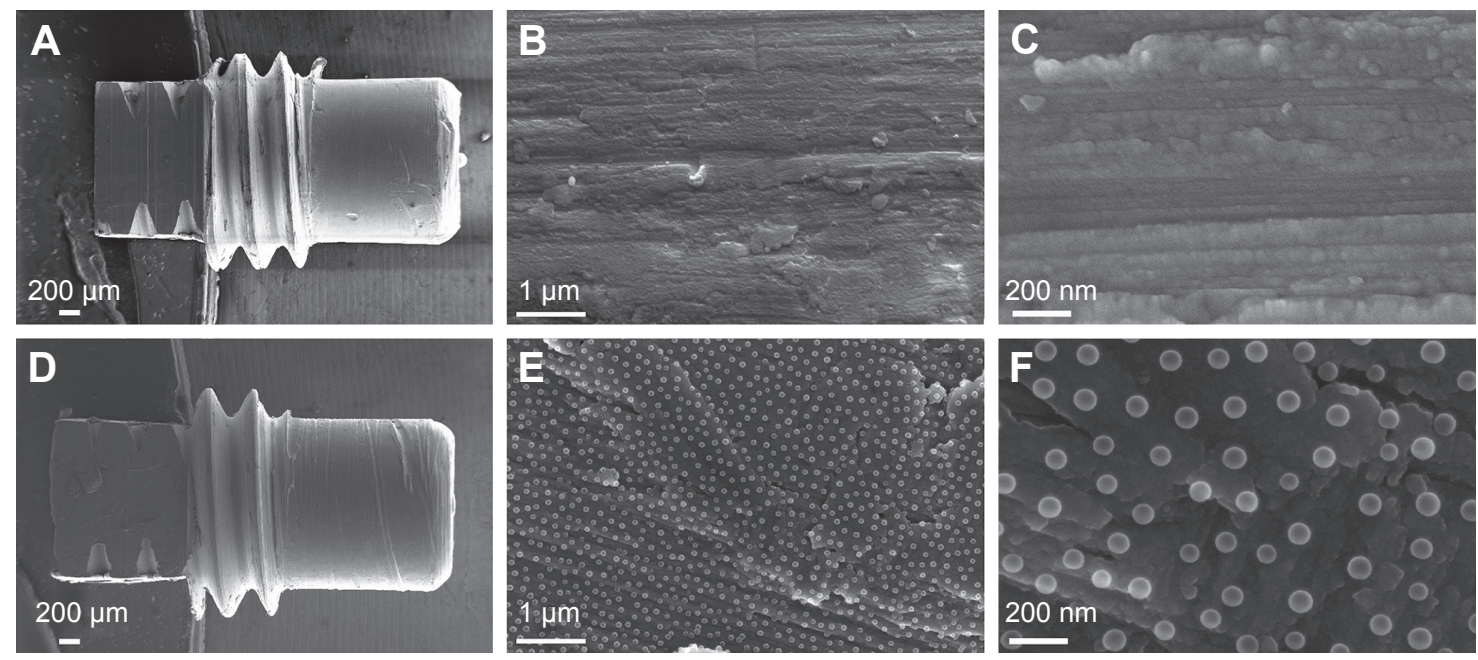

Figure I SEM analysis of the surface topography.

Notes: The low magnification SEM micrographs show the overall geometry of the Ma (A) and the Nano (D) implants. The higher magnification SEM micrographs show the underlying surfaces at the micron scale of $\mathrm{Ma}(\mathbf{B})$ and $\mathrm{Nano}(\mathbf{E})$ implants. The high-resolution SEM micrographs show the surface of the Ma (C) and the superimposed nanotopography on the Nano implants (F).

Abbreviations: SEM, scanning electron microscopy; Ma, machined; Nano, nanopatterned.

attachment area to avoid the displacement and aggregation due to capillary forces during the drying process. This was achieved by soaking the implants in a hot (close to boiling) water bath, which raised the temperature of the nanoparticles to the glass transition temperature. After the heat treatment, the implants were rinsed in Milli-Q water (Millipore Corporation) and blow-dried by nitrogen. In the next step, the adsorbed spherical polymeric nanoparticles on the implant surfaces were deformed to a semispherical shape by melting them in an oven at $105^{\circ} \mathrm{C}$ for 1 minute. In order to achieve a homogeneous chemistry on the implant surfaces, a $10 \mathrm{~nm}$ Ti layer was sputter-coated (FHR MS150 magnetron sputter, $5 \times 10^{-5} \mathrm{mbar}, 0.33 \mathrm{~kW}$; FHR Anlagenbau GmbH, OttendorfOkrilla, Germany) on all the implants. Finally, the implants were stored in $70 \%$ ethanol until surgery.

\section{Implant surface characterization}

Surface topography at the nanoscale level was investigated by scanning electron microscopy (SEM; Supra 60 VP; Carl Zeiss NTS GmbH, Oberkochen, Germany). The parameters related to nanofeature size, distribution density, and coverage were obtained by SEM image analysis (average of seven images) using ImageJ v1.4 software (NIH, Bethesda, MD, USA).

Surface roughness at the micron scale was analyzed using an optical profiler (Wyko NT 1100; Veeco, Plainview, NY, USA) in vertical scanning interferometry mode. Surface roughness parameters were calculated using SPIP v.3 software (Image Metrology A/S, Hørsholm, Denmark). Because the dimensions of the nanopatterned spheres being much smaller than the lateral resolution of the optical profiler, only the surface of the control implant group (Ma implants) was analyzed $(\mathrm{n}=3)$.

Chemical composition of the implants, after nanopatterning and sputter-coating, was analyzed by energy-dispersive X-ray spectroscopy (EDS) system (IXRF Systems, Austin, TX, USA) integrated into Supra 60 VP SEM instrument (Carl Zeiss NTS GmbH). EDS analysis was performed using the following settings: $15 \mathrm{keV}$ acceleration voltage, high current mode, $35^{\circ}$ takeoff angle, 30 -second elapsed live time, time constant set to $2,1,800-2,300$ counts/s signal intensity on electronically cooled silicon drift detector, and ZAF correction.

\section{Animal surgery}

The animal experiments were approved by the University of Gothenburg Local Ethical Committee for Laboratory Animals (Dnr 301-2009) following the national guidelines of animal welfare. Twenty-one male Sprague Dawley rats (250-380 g), fed on a standard pellet diet and water, were used. The surgical procedure was performed under general anesthesia induced by isoflurane inhalation ( $4.1 \%$ with an air flow of $650 \mathrm{~mL} / \mathrm{min})$ in a Univentor 410 anesthesia unit (Univentor Ltd, Zejtun, Malta). Anesthesia was maintained by continuous administration of isoflurane ( $2.3 \%$ with an air flow of $450 \mathrm{~mL} / \mathrm{min})$ via a mask. After shaving, cleaning (chlorhexidine $0.5 \mathrm{mg} / \mathrm{mL}$ ), and infiltration with local anesthetic solution ( $1 \mathrm{~mL}$ xylocaineadrenalin $10 \mathrm{~mL} / \mathrm{mL}+5 \mu \mathrm{g} / \mathrm{mL}$ ), the medial aspect of the proximal tibial metaphysis was exposed through skin incision, 
muscle reflection, and periosteal elevation. Two sites were prepared in each metaphysis (proximally and distally) using sequential enlarging with burs $(\varnothing 1.4$ and $\varnothing 1.8 \mathrm{~mm}$, respectively), under profuse saline irrigation. A total of 84 implants were used: 42 Nano and $42 \mathrm{Ma}$. They were installed using a predesigned schedule to ensure maximum rotation of the two different implants (proximal/distal sites, right/left sides). After installation, the skin was closed in layers, subcutaneously using resorbable polyglactin sutures (Vicryl 4-0; Ethicon, Inc., Somerville, NJ, USA) and externally using resorbable poliglecaprone sutures (Monocryl 4-0; Ethicon, Inc.). Each rat received subcutaneous injection of buprenorphine analgesic (Temgesic 0.03 mg/kg; Reckitt and Coleman Ltd, Hull, UK) postoperatively. The rats were housed in groups and provided with food and water ad libitum. The retrieval of the implants was performed at three time points, 3, 6, and 28 days after implantation ( 7 rats [14 implants from each type] at each time point). The animals were euthanized using an overdose of barbiturate (Pentobarbitalnatrium vet. APL $60 \mathrm{mg} / \mathrm{mL}$; APL, Umeå, Sweden). The skin and the subcutaneous tissues were reopened and the implants were retrieved. The implant retrieval was performed either manually, using a screwdriver (for quantitative polymerase chain reaction [qPCR] and SEM/ EDS), or en bloc, together with surrounding tissue (for histology and immunohistochemistry).

\section{Quantitative polymerase chain reaction}

After 3, 6, and 28 days, unscrewed implants with adherent biological material (8 specimens/surface/time point; $\mathrm{n}=8$ ) were placed in RNAlater solution (QIAGEN GmbH, Hilden, Germany), stored at $4^{\circ} \mathrm{C}$ overnight, and then at $-80^{\circ} \mathrm{C}$ until analysis. DNAse treatment was performed in order to eliminate any contamination from genomic DNA. Total RNA was extracted using RNeasy Micro kit (QIAGEN GmbH) according to the manufacturer's instructions. Primers for the six sharp genes, TNF- $\alpha, A L P, O C$, Runx2, CatK and CTR, was designed using the Primer3 web-based software. ${ }^{15}$ Assays were purchased from TATAA Biocenter AB, Göteborg, Sweden. All reverse transcriptions were performed using an iScript cDNA Synthesis Kit (Bio-Rad Laboratories, Inc., Hercules, CA, USA). cDNA was stored at $-20^{\circ} \mathrm{C}$ until qPCR analysis. The analysis was performed on all samples, with the assays targeting the six different mRNA transcripts (TNF- $\alpha, A L P, O C, R u n x 2$, CatK, and $C T R$ ) and three reference genes (YWHAZ, HPRT1, and $T B P$ ). The analysis was performed using $10 \mathrm{~mL}$ reaction volume in duplicates on the LightCycler480 Instrument (Roche Diagnostics Corporation, Indianapolis, IN, USA) with iQTM SYBR Green Supermix (Bio-Rad Laboratories Inc.). The expression profiles of the reference genes were evaluated using geNorm ${ }^{16}$ and NormFinder ${ }^{17}$ softwares. The most stable expression was achieved by YWHAZ (compared to HPRT1 and TBP), and it was therefore chosen as the reference gene. The quantities of the target genes were normalized to the selected reference gene. The normalized relative quantities were calculated using the delta-delta $\mathrm{Cq}$ method and 90\% PCR efficiency $\left(k \times 1.9^{\Delta \Delta \mathrm{Cq}}\right) .{ }^{18}$

\section{Histology and immunohistochemistry}

After 3, 6, and 28 days, block specimens (3 specimens/ surface/time point, $n=3$ ) were used for histological and immunohistochemical analyses. The implant-bone specimens were fixed in formaldehyde, decalcified in $10 \%$ ethylenediaminetetraacetic acid for 10-12 days, and then embedded in paraffin. While the paraffin was still in melting stage, the implants were completely unscrewed and the paraffin embedding procedure was continued. The idea behind removing the implant at this stage was to preserve the implant-bone interface as intact as possible. Subsequently, 3-5 $\mu \mathrm{m}$ thick sections were produced, mounted on glass slides, and stained with hematoxylin and eosin. Paraffinembedded sections for immunohistochemistry were mounted on poly-L-lysine slides (Menzel GmbH and Co KG, Braunschweig, Germany) and incubated with primary antibodies against CD163 and periostin (Abcam, Cambridge, UK). The CD163 antibody targets surface receptors on monocytes and macrophages, whereas periostin antibody targets the protein intracellularly, in osteoprogenitor cells, as well as extracellularly, indicating an active intramembranous bone formation. Negative controls were prepared by the omission of the primary antibody and incubation with $1 \%$ bovine serum albumin in phosphate-buffered saline. The hematoxylin and eosin and immunohistochemistry (CD163 and periostin) sections, representing the healing periods of 3, 6, and 28 days, were evaluated qualitatively by light microscopy (Nikon Eclipse 600; Nikon Instruments, Tokyo, Japan). In addition, the CD163- and periostin-positively stained cells were counted manually using a high-power field (magnification 40×). The positively stained cells were counted along the interface, extending $200 \mu \mathrm{m}$ from the implant surface, and expressed as number of cells $/ \mathrm{mm}^{2}$. The quantifications were only performed on the 3-day sections $(n=3)$, where well-preserved sections were used, showing an intact entire interface at both sides of the implant. Quantifications at 6 and 28 days were hindered due to major difficulty in obtaining adequate sections, and hence standardization 
of the number of observations and the region-of-interest was not possible.

\section{SEM and EDS of retrieved implants}

Implants retrieved after 3, 6, and 28 days (3 specimens/ surface/time point, $n=3$ ) were fixed in a modified Karnovsky's solution (2\% paraformaldehyde, $2.5 \%$ glutaraldehyde in $0.05 \mathrm{M}$ sodium cacodylate buffer, $\mathrm{pH} 7.2-7.4$ ). Specimens were then rinsed with sodium cacodylate buffer and subsequently impregnated with a conductive, metallic layer of osmium, using a modified osmium-thiocarbohydrazide-osmium technique. Specimens were then dehydrated in graded series of ethanol and dried with hexamethyldizilasane for $2 \times 5$ minutes. Specimens were mounted on stubs by using carbon-coated adhesive tape. In case of insufficient conductivity, specimens were subjected to an additional sputter-coat with palladium. All specimens were examined in a ZEISS 982 Gemini field emission scanning electron microscope (Carl Zeiss, Oberkochen, Germany), operating at $3-7 \mathrm{kV}$, to evaluate the surfaces and adherent biological material.

Moreover, the cylindrical part of the implants retrieved after 28 days was evaluated by EDS analysis to detect the presence of mineralized tissue adherent to the surface. The EDS scans were performed in area mode using the instrumentation and settings similar to those described in the "Surface characterization" section.

\section{Statistics}

Statistical comparisons of the gene expression were performed using nonparametric statistical tests. Mann-Whitney test was used to determine the statistically significant differences between the two implant types at each time period. Furthermore, Kruskal-Wallis test followed by Mann-Whitney test was used to determine statistically significant differences among the three different time periods. $P$-values of less than 0.05 were considered to be significant. All statistical tests were done with IBM $^{\circledR}$ SPSS $^{\circledR}$ Statistics Version 22 (IBM Corporation, Armonk, NY, USA). On the graphs, data is presented as mean values \pm standard error of the mean, where statistically significant differences $(P<0.05)$ are indicated by small letters $\mathrm{a}-\mathrm{d}$.

\section{Results}

\section{Implant surface characterization}

The SEM analysis of the Nano implants revealed that the polystyrene nanoparticles transformed into semispherical nanostructures due to heat treatment and plasma shrinkage processes involved in the fabrication. The nanostructures uniformly covered the surface of the cylindrical part of the implant and were directly superimposed on the original Ma microscale topography (Figure 1B and E). The superimposed nanostructures were well defined in terms of shape (semispherical protrusions), size ( $79 \pm 6 \mathrm{~nm}$ diameter), and distribution density ( $31 \pm 2$ particles $/ \mu \mathrm{m}^{2}$, average center-tocenter interparticle distance of $165 \pm 28 \mathrm{~nm}$ ). This corresponds to $16 \% \pm 2 \%$ projected coverage of the surface and induced surface area by $34 \% \pm 4 \%$.

The cylindrical part of the implants observed by SEM and optical profilometry revealed the typical microscale topography of the Ma implants dominated by machininginduced microgrooves aligned perpendicularly to the implant turning axis (Figure 1B and C). At a lower scale, the microgrooves exhibited shallow pits and flake-shape protrusions. The quantified microscale surface roughness parameters are summarized in Table 1.

The EDS analysis showed the presence of Ti, O, C, Al, and $\mathrm{Si}$ in the probing volume (1-3 $\mu \mathrm{m}$ penetration depth) for both implant types. The spectra were dominated by $\mathrm{Ti}$ and $\mathrm{O}$ signals at weight concentrations of $90.2 \% \pm 0.1 \%$ and $7.5 \% \pm 0.2 \%$, respectively, for both implant types. Carbon weight concentration was $2.1 \% \pm 0.2 \%$, which most likely represented a hydrocarbon layer adsorbed from the ambient air. $\mathrm{Al}$ and $\mathrm{Si}$ were detected at trace amounts $(<0.2 \%)$ and most likely originated from the coating equipment (Al vacuum chamber) and the storage container (glass vial), respectively.

\section{Gene expression analyses}

Gene expression of selected markers of major biological processes during bone healing and regeneration at the boneimplant interface was evaluated (Figure 2). Markers for

Table I Implant roughness characterization of the machined implants using optical profiler

\begin{tabular}{llll}
\hline Roughness parameter & Standard & Mean (SEM) & Unit \\
\hline$S_{a}$ & DIN 4768 & $0.73(0.01)$ & $\mu \mathrm{m}$ \\
$S_{\mathrm{q}}$ & ISO 4287/I & $0.94(0.02)$ & $\mu \mathrm{m}$ \\
$S_{\text {sk }}$ & ISO 4287/I & $-0.5(0.19)$ & $\mathrm{N} / \mathrm{A}$ \\
$S_{\mathrm{ku}}$ & ANSI B.46.I9 & $3.5(0.45)$ & $\mathrm{N} / \mathrm{A}$ \\
$S_{z}$ & ANSI B.46.I & $6.1(0.26)$ & $\mu \mathrm{m}$ \\
$S_{\mathrm{ds}}$ & N/A & $0.5(0.15)$ & $\mu \mathrm{m}^{-2}$ \\
$S_{\mathrm{dr}}$ & N/A & $20(3.02)$ & $\%$ \\
$S_{\mathrm{ci}}$ & N/A & $1.5(0.08)$ & $\mathrm{N} / \mathrm{A}$ \\
\hline
\end{tabular}

Note: The data shows the mean and SEM $(n=3)$.

Abbreviations: $S_{\mathrm{a}}$, roughness average; $S_{q}$, root mean square; $S_{\mathrm{sk}}$, surface skewness; $S_{\mathrm{ku}}$, surface kurtosis; $S_{z^{\prime}}$, ten point height; $S_{d s}$, density of summits; $S_{d r}$, surface area ratio; $S_{c^{\prime}}$, core fluid retention index; N/A, not applicable; SEM, standard error of the mean. 
A

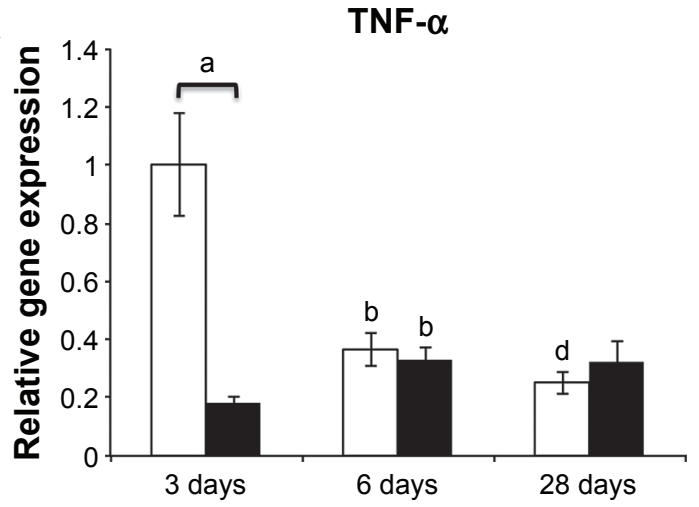

C

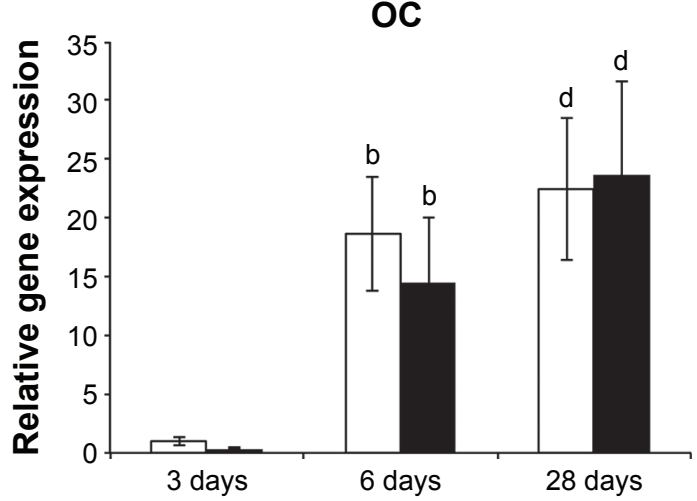

E

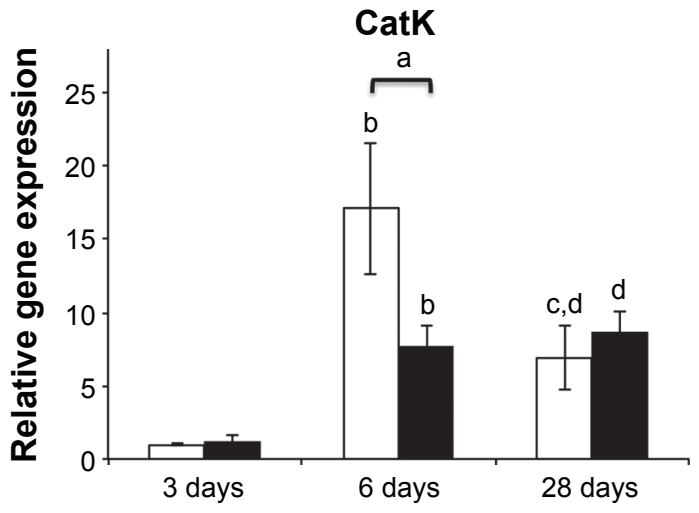

B

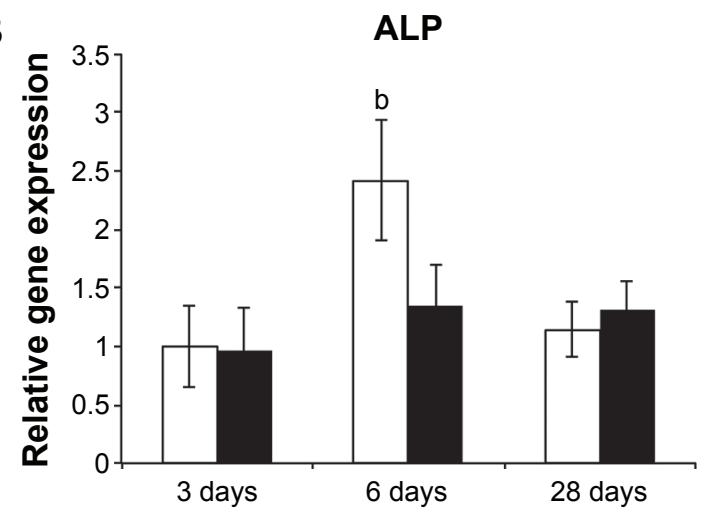

D

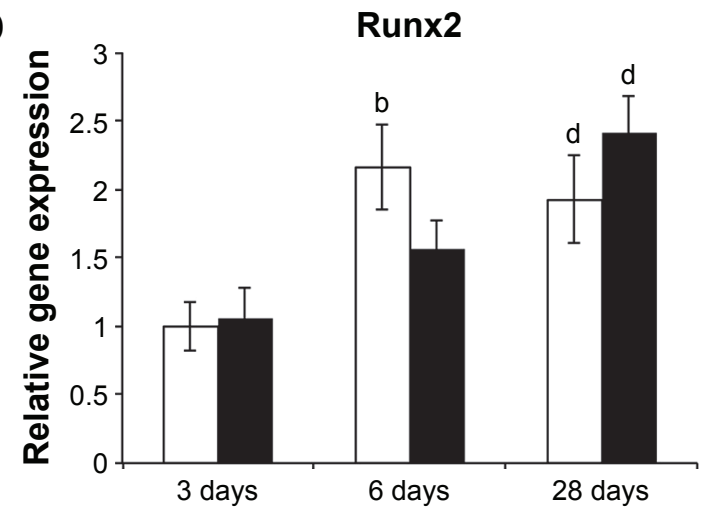

F

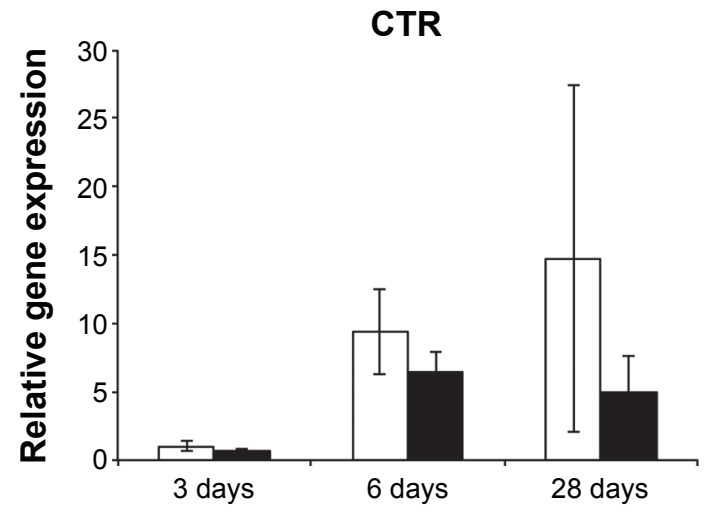

$\mathrm{Ma}$

Nano

Figure 2 Gene expression analysis of the implant-adherent cells.

Notes: The column graphs show the gene expression in the implant-adherent cells of Ma and Nano titanium implants. The implants were retrieved, by unscrewing, after 3 , 6, and 28 days. (A) TNF- $\alpha$. (B) ALP. (C) OC. (D) Runx2. (E) CatK. (F) CTR. The data show the mean and standard error of the mean (n=8). Statistically significant differences $(P<0.05)$ are indicated by small letters: $a=$ statistically significant difference between the two implant types at each time point; $b=$ statistically significant difference between 3 and 6 days for each implant type; $c=$ statistically significant difference between 6 and 28 days for each implant type; $d=$ statistically significant difference between 3 and 28 days for each implant type.

Abbreviations: Ma, machined; Nano, nanopatterned.

inflammatory, osteogenic, and osteoclastic activities were analyzed in the cells adherent to the Ma and Nano titanium implants, retrieved by unscrewing after 3,6 , and 28 days of implantation.

The expression of TNF- $\alpha$ at 3 days was 5.5 -fold significantly lower in the cells adherent to the Nano implants compared to the Ma implants (Figure 2A). TNF- $\alpha$ expression levels were not significantly different between the two implants at 6- and 28-day periods. The temporal expression of TNF- $\alpha$ at the Nano implants revealed slight, yet significant, increase from 3 to 6 days and remained unchanged thereafter. On the other hand, a peak expression of TNF- $\alpha$ was detected 
at the Ma implants at 3 days, significantly decreased after 6 days, and was maintained at the same level after 28 days.

With respect to the analyzed osteogenic markers, although a trend of 1.8-fold higher expression of $A L P$ was detected at the Ma compared to Nano implant at 6 days (Figure 2B), this was not statistically significant. With respect to Runx 2 and $O C$ gene expression, no statistically significant differences were found between the Ma and Nano implants at any of the evaluation periods (Figure $2 \mathrm{C}$ and $\mathrm{D}$ ). The temporal course for all analyzed osteogenic genes at the Ma implants was characterized by statistically significant increase from 3 to 6 days, followed by a slight (albeit not significant) increase $(O C)$ or decrease (ALP and Runx2) after 28 days (Figure 2B-D). At the Nano implants, the temporal expression of $A L P$ showed relatively similar levels at the three evaluated periods (Figure 2B). The temporal expression of $O C$ at the Nano implants showed a statistically significant increase from 3 to 6 days, followed by a slight (albeit not significant) increase after 28 days (Figure 2C). There was also a trend for temporal increase of Runx 2 over time; however, this was not statistically significant.

The expression of osteoclastic activity marker $C a t K$ was 2.2-fold significantly lower at the Nano implants when compared to Ma implants at the 6-day time period (Figure 2E). No major difference was detected at the other time periods (ie, 3 and 28 days). The temporal expression of $C a t K$ at the Ma implants revealed a significant increase from 3 to 6 days, followed by significant decrease from 6 to 28 days. At the Nano implants, CatK temporal expression showed significant increase from 3 to 6 days, but was maintained at the same level from 6 to 28 days. The expression of CTR showed large variability among the animals and did not reveal any significant differences between the implant surfaces and the time points (Figure 2F).

\section{Histology and immunohistochemistry}

At the early time of retrieval, ie, 3 days of healing, wellorganized granulation tissue could be observed covering the cylindrical part of the implant (Figure 3A and G). Cells adjacent to the implant appeared flattened and were parallel to the surface of the removed implant (Figure 3D and J). Signs of new bone formation were evident in the tissue surrounding the implant (Figure 3D and J). At 6th day, considerable amount of woven bone was observed extending from the endosteum and surrounding the implant (Figure 3B and $\mathrm{H})$. The newly formed woven bone was characterized by globular appearance with numerous large osteocytes (Figure $3 \mathrm{E}$ and $\mathrm{K}$ ). The bone formation was more evident in the endosteal regions where a downgrowth from the cortical bone could be observed along the implant surface.
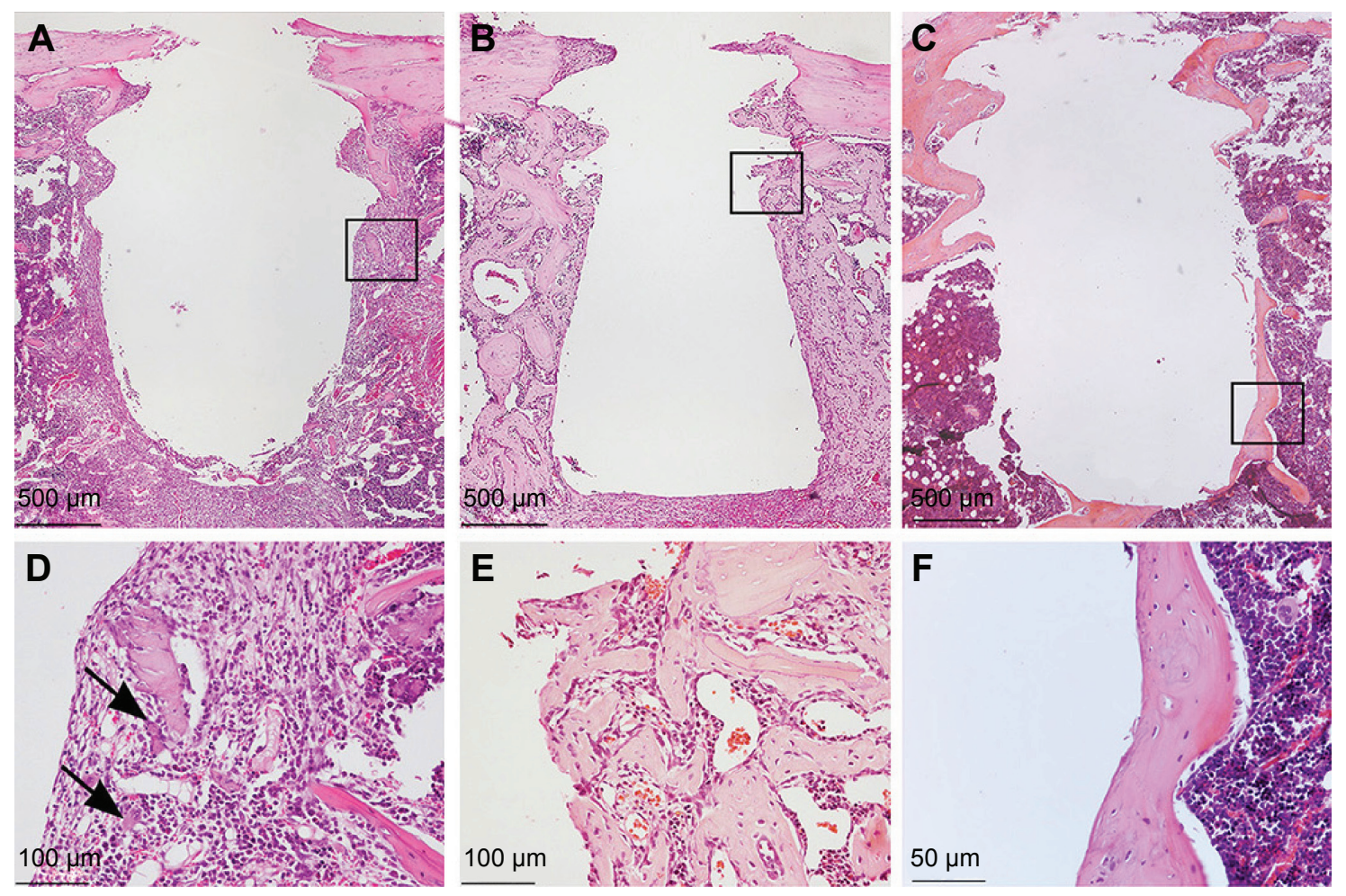

Figure 3 (Continued) 

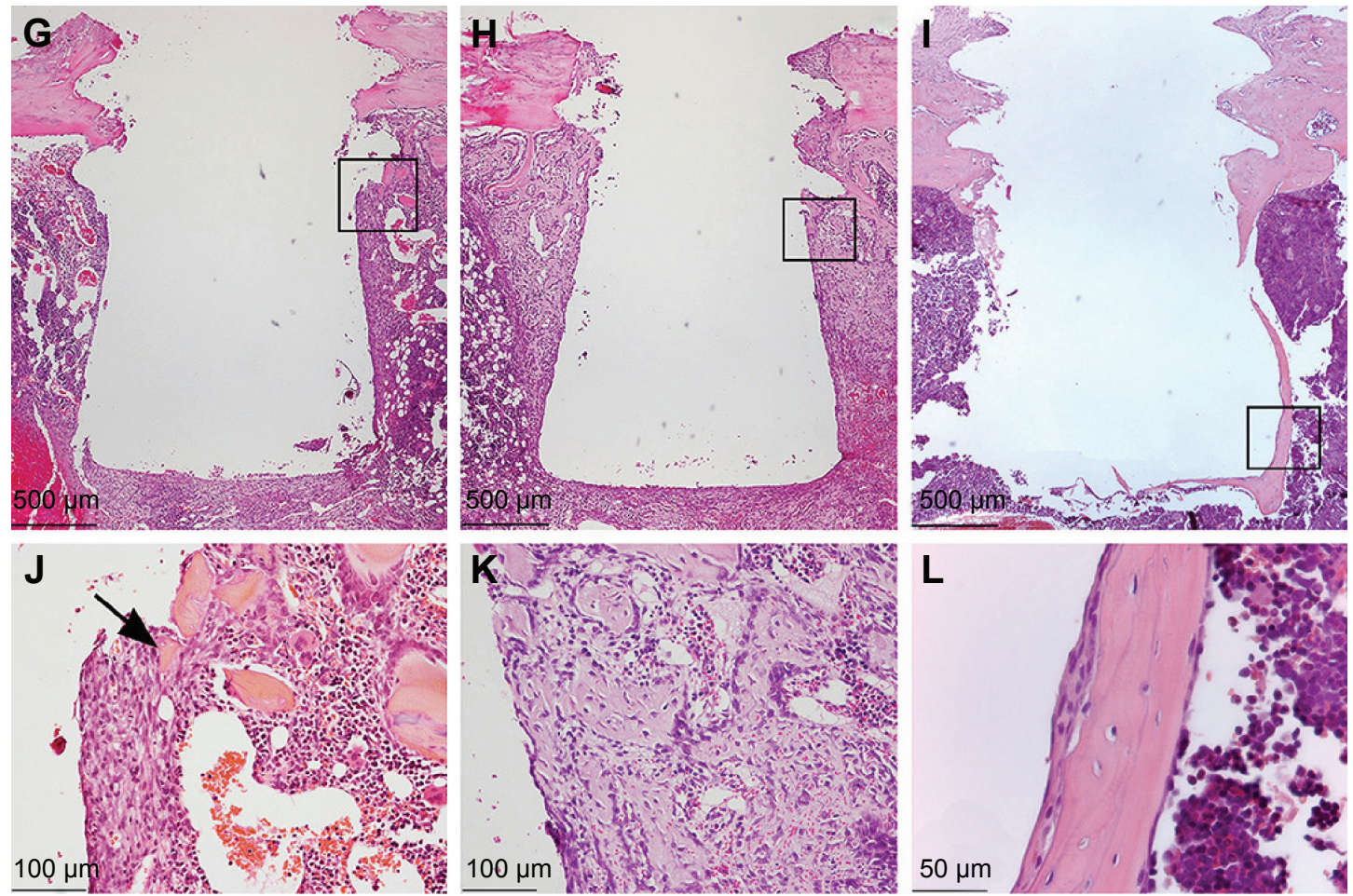

Figure 3 Histological analysis of the tissues around the implants.

Notes: The survey light micrographs of paraffin-embedded and H\&E stained sections show the morphology of the tissue around Ma (A-F) and Nano (G-I) implants, 3 days $(\mathbf{A}, \mathbf{D}$, $\mathbf{G}$, and $\mathbf{~ J ) , ~} \mathbf{6}$ days (B, E, H, and $\mathbf{K})$, and 28 days (C, F, I, and $\mathbf{L})$ after implantation. Implants were gently unscrewed during paraffin embedding in order to reduce artifactual damage to the tissue during separation of implant from tissue. After 3 days, (A, D, G, and $\mathbf{J})$, an organized granulation tissue with localized sites with remaining hematoma is seen. Bone formation in the threads becomes evident in the form of woven bone indicated by arrows. After 6 days, (B, E, $\mathbf{H}$, and $\mathbf{K})$, endosteal downgrowth as well as de novo bone formation can be observed. No inflammatory infiltrates are detected. After 28 days, (C, F, I, and $\mathbf{L})$, the early-formed woven bone is completely remodeled and replaced by mature lamellar bone with flattened osteocytes. The black boxes in $(\mathbf{A}-\mathbf{C})$ and $(\mathbf{G}-\mathbf{I})$ represent the areas shown in higher magnifications as (D-F) and (J-L), respectively.

Abbreviations: H\&E, hematoxylin and eosin; Ma, machined; Nano, nanopatterned.

At 28th day, the early-formed woven bone had considerably remodeled, resulting in a relatively thin mature bone surrounding the implant (Figure $3 \mathrm{C}$ and $\mathrm{I}$ ). This mature bone was characterized by a lamellar appearance with relatively small and flattened osteocytes (Figure 3F and L).

Positively stained CD163 cells (monocytes/macrophages) were seldom observed in the tissue corresponding to the threaded part of the implant (cortical region), regardless of the implant type and healing time point (Figure 4). At 3rd day, CD163-positive cells in the marrow part appeared considerably less at the Nano surfaces compared to the Ma surfaces (Figure 4A, D, and G). At 6th day, CD163-positive monocytes/macrophages were less frequently encountered for both implant types (Figure 4B and E), while at 28 days, very few immunostained monocytes/macrophages could be detected (Figure 4C and F).

The immunoreactivity of periostin exhibited two characteristic features depending on the time of observation (Figure 5). At the early 3-day time period, periostin reactivity was largely confined within the positive cells, and to a lesser extent, as diffuse extracellular staining around those cells
(Figure 5A and D). During this period, a relatively higher number of positively stained cells could be observed in close vicinity to the Nano implants compared to the Ma implants (Figure 5A, D, and G). At 6th day, periostin reactivity appeared mainly as an interstitial diffuse staining around and within the newly formed woven bone globules (Figure 5B and $\mathrm{E})$. At 28th day, a considerable reduction in periostin reactivity was observed, although a few regions of diffuse staining were still detected at the interface. This observation of a few diffusely stained regions in the interface was mainly restricted to the Nano implants (Figure 5C and F).

\section{SEM and EDS analyses of retrieved implants}

After 3 days, the implant surface was unevenly covered with a fibrinous material with entrapped red blood cells and leukocytes (Figure 6A, B, I, and J). The exposed areas of the retrieved implants revealed either the Ma surface of the control implants (Figure 6C) or the well-preserved nanoscale features of the Nano implants (Figure 6K). At 6th day, the adherent biological material appeared denser and more 

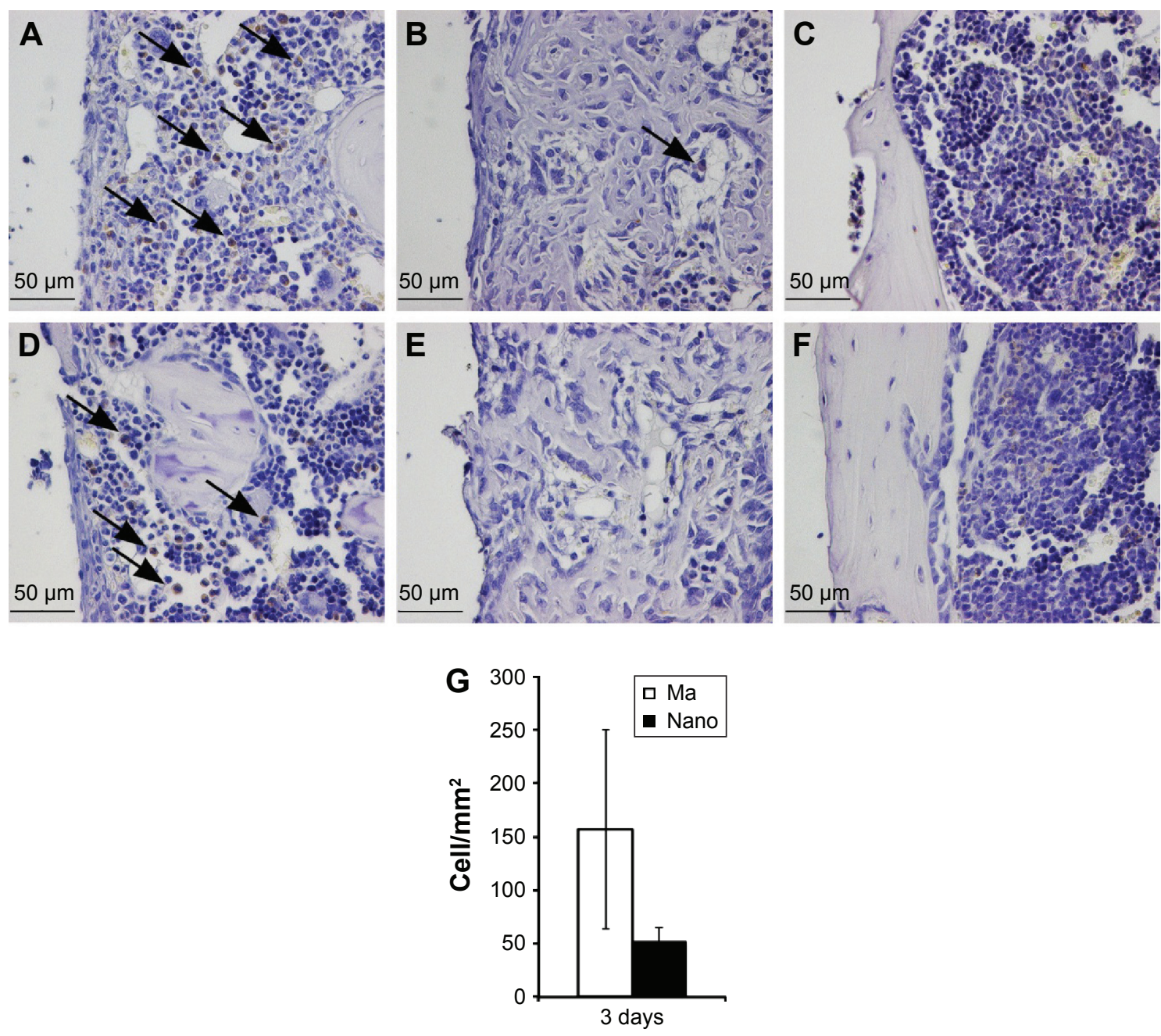

Figure 4 Immunohistochemical analysis of CDI63-positive cells.

Notes: The sections show the positively stained cells, monocytes and macrophages, at $\mathrm{Ma}(\mathbf{A}-\mathbf{C})$ and Nano (D-F) implants. The analysis was performed at 3 days (A and $\mathbf{D})$, 6 days ( $\mathbf{B}$ and $\mathbf{E}$ ), and 28 days ( $\mathbf{C}$ and $\mathbf{F}$ ). At 3 days, a higher amount of CDI63-positive cells can be seen at the Ma implants compared to the Nano implants (denoted by arrows). After 6 days, a low number of stained cells can be seen on both surfaces, while at 28 days, monocytes/macrophages are not evident in the periimplant tissue. The column graph (G) shows the quantification of CDI63-positively stained cells counted along the interface, extending $200 \mu \mathrm{m}$ from the implant surface, and expressed as number of cells $/ \mathrm{mm}^{2}$. The quantification was only performed on the 3 -day sections $(\mathrm{n}=3)$, where well-preserved sections were used, showing an intact entire interface, at both sides of the implant.

Abbreviations: Ma, machined; Nano, nanopatterned.

organized compared to the material at 3 days (Figure 6D, E, I, and M). At this time point (6 days), mesenchymal-like cells, with a relatively large size $(>10 \mu \mathrm{m})$, were more evident (Figure 6D and I) compared to the smaller size red blood cells and leukocytes, which predominated at 3 days. In addition, the denuded regions of the implants showed that the Ma and Nano surfaces were covered with a thick proteinaceous layer, but the characteristic morphology of the $\mathrm{Ma}$ and Nano surfaces could still be observed (Figure 6F and N). After 28 days, the implant-adherent material assumed bonelike appearance at several locations of the retrieved implants (Figure 6G, H, O, and P).

EDS measurements were performed on two rectangular areas along the axis of the cylindrical part of the 28-day-retrieved implants. This was in order to analyze the largest possible area of the retrieved implant while avoiding systematic errors due to electron beam angle variation across the cylinder axis (Figure 7A). The elemental analysis showed a higher amount and more localized distribution of $\mathrm{Ca}$ and $\mathrm{P}$ at the Nano implants compared to the Ma implants (Figure 7).

\section{Discussion}

These results provide a direct evidence of the role of nanotopography, per se, on the healing events of osseointegration. The mechanisms of bone promotion by nanocues in vivo remain to be clarified. Support for stimulatory effects of nanofeatures on the adhesion and differentiation of mesenchymal 

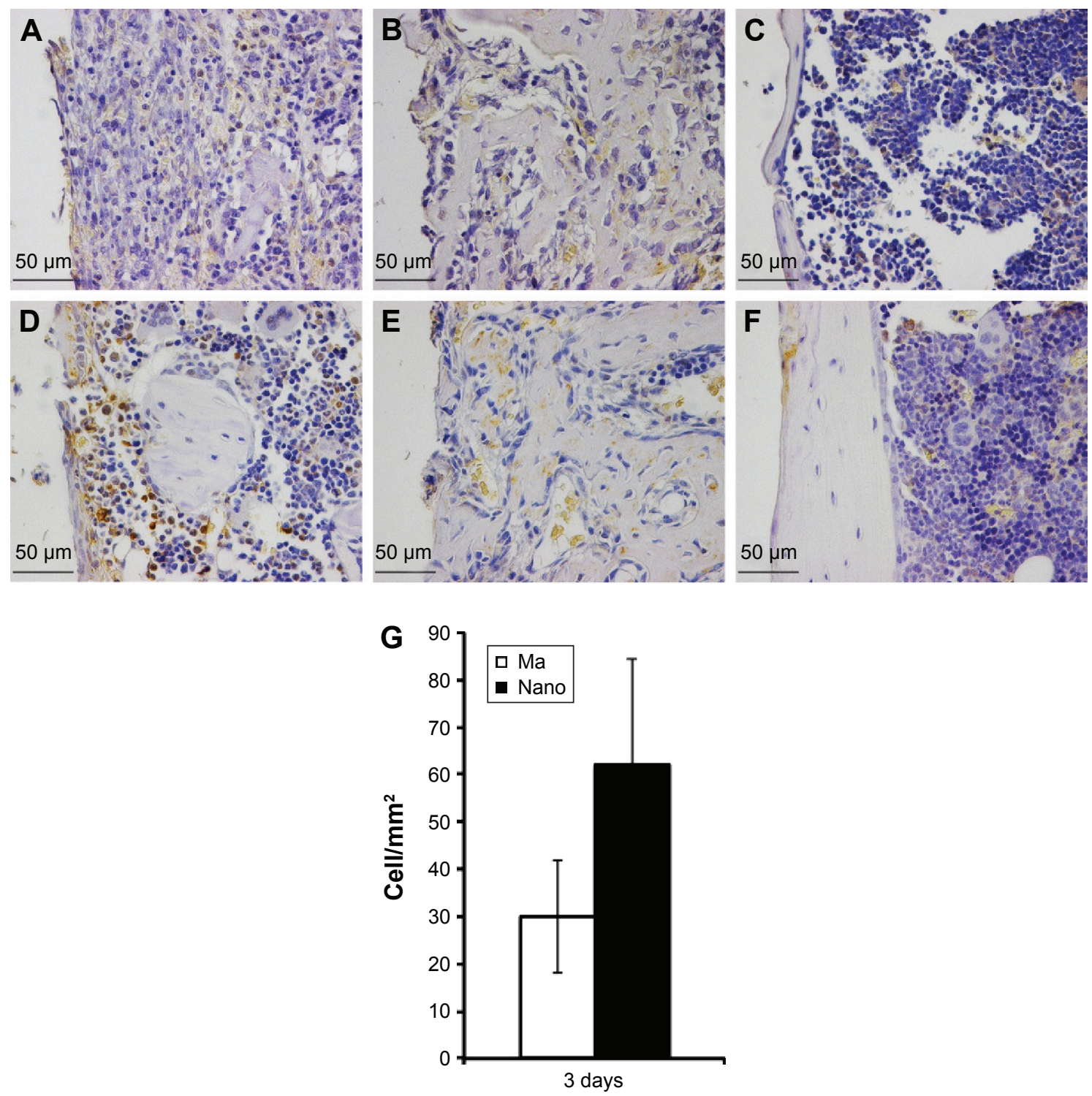

Figure 5 Immunohistochemical analysis of periostin-positive cells and extracellular protein.

Notes: The sections show the positively stained cells at Ma $(\mathbf{A}-\mathbf{C})$ and Nano $(\mathbf{D}-\mathbf{F})$ implants. The analysis was performed at 3 days $(\mathbf{A}$ and $\mathbf{D}), 6$ days $(\mathbf{B}$ and $\mathbf{E})$, and 28 days $(\mathbf{C}$ and $\mathbf{F})$. At 3 days, the implants with nanostructures showed a relatively higher degree of periostin staining both within the cells and in the extracellular matrix (A versus D). At 6 and 28 days, the staining became more diffuse and sparse in the extracellular space with no apparent differences between the two implant types. The column graph (G) shows the quantification of periostin-positively stained cells counted along the interface, extending $200 \mu \mathrm{m}$ from the implant surface, and expressed as number of cells $/ \mathrm{mm}^{2}$. The quantification was only performed on the 3-day sections $(n=3)$, where well-preserved sections were used, showing an intact entire interface, at both sides of the implant.

Abbreviations: Ma, machined; Nano, nanopatterned.

stem cells (MSCs) has largely been provided in vitro., ${ }^{3,19-26}$ Nanostructures support the anabolic path of bone formation, but less information is available with respect to the effect of nanostructures on osteoclasts. The latter is likely of equal importance by virtue of the important role of osteoblastosteoclast coupling and regulation of bone formation and remodeling during osseointegration. ${ }^{5,27}$

An alternative path for the enhancing effect of nanostructures on osseointegration could be via the moderation of the early inflammatory response associated with the surgical trauma and subsequent implantation of the titanium implant. A novel and important observation in this study was the finding of less macrophages and an attenuated inflammatory response at the Nano surfaces. A possible explanation for the reduced macrophage influx could be an inhibition of chemotactic and chemokinetic signals elicited during the postoperative phase. Such an assumption is at least partly supported by the observation of reduced expression of a major proinflammatory and chemotactic cytokine, TNF- $\alpha$. This hypothesis needs confirmation by further studies of 

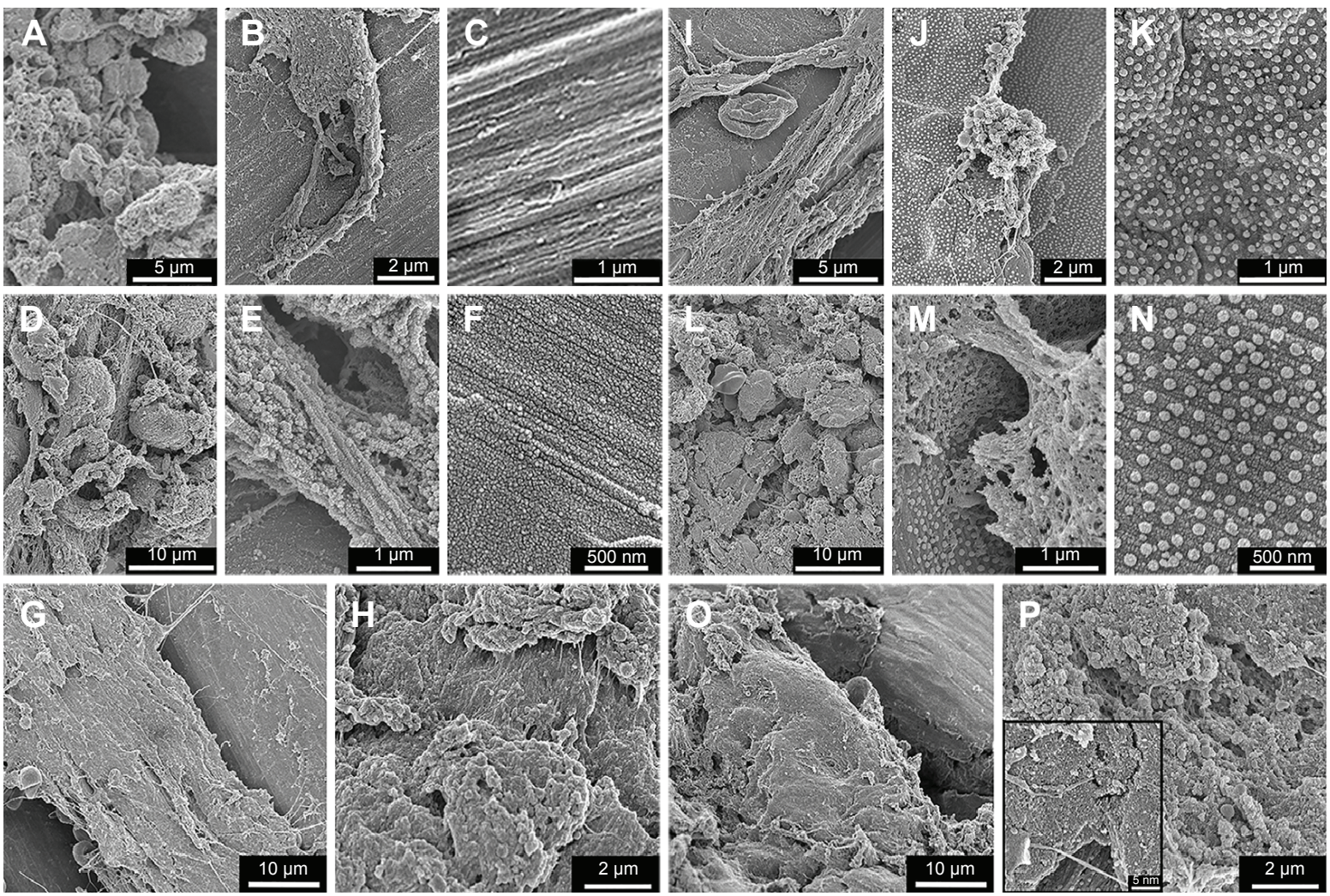

Figure 6 SEM analysis of retrieved implants.

Notes: The SEM survey micrographs show the Ma (A-H) and Nano (I-P) implants after 3 days (upper panel), 6 days (middle panel), and 28 days (bottom panel) of implantation. At 3 days, the retrieved implants appeared partially covered with fibrinous material, which was entrapped with numerous erythrocytes and leukocytes (B for $\mathrm{Ma}$ and I for Nano implants). The higher magnification at this time point shows cells extending filopodia on the surfaces (A for Ma and J for Nano implants), which, in many occasions, appeared to interact with nanostructures $(\mathbf{J})$. $(\mathbf{C})$ and $(\mathbf{K})$ show exposed areas of the implants, where the $\mathrm{Ma}(\mathbf{C})$ and $\mathrm{Nano}$ (K) surfaces can be observed. After 6 days, the relative proportion of the cellular material adherent to either implant type has increased ( $\mathbf{D}$ for Ma and $\mathbf{L}$ for Nano implants). Yet, at this time point, some areas are exposed which reveal the underlying $\mathrm{Ma}(\mathbf{E})$ and $\mathrm{Nano}(\mathbf{M})$ implant surfaces. The higher magnifications of the $\mathrm{Ma}(\mathbf{F})$ and $\mathrm{Nano}(\mathbf{N})$ surfaces show a relative increase in the adsorbed protein layer, but still the characteristic morphology of the Ma and Nano surfaces can be observed. After 28 days, the adherent material was bone-like tissue observed at several locations of the retrieved $\mathrm{Ma}(\mathbf{G}, \mathbf{H})$ and $\operatorname{Nano}(\mathbf{O}, \mathbf{P})$ implants. At some locations where the implant was denuded from the adherent tissue, the Nano implant surface can be observed (insert in $\mathbf{P}$ ).

Abbreviations: SEM, scanning electron microscopy; Ma, machined; Nano, nanopatterned.

A
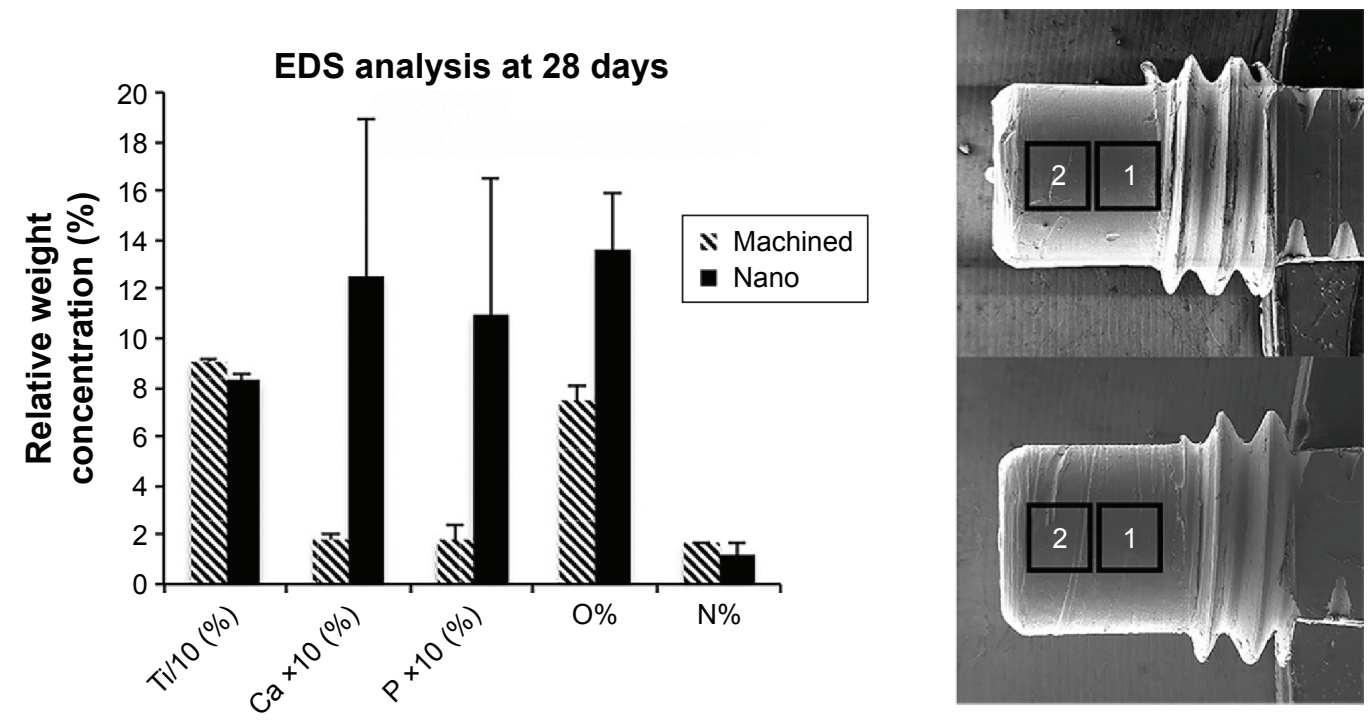

Figure 7 (Continued) 
B

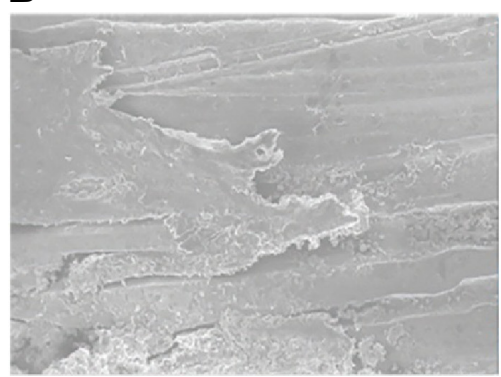

$\mathbf{P}$

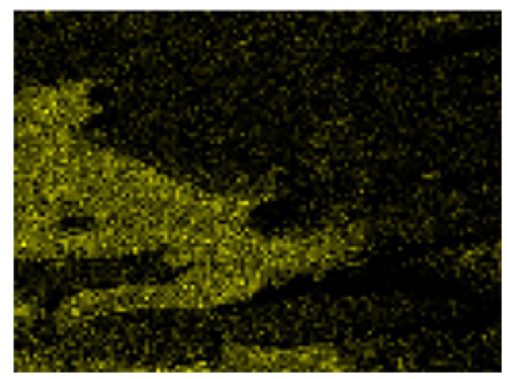

$\mathrm{Ti}$

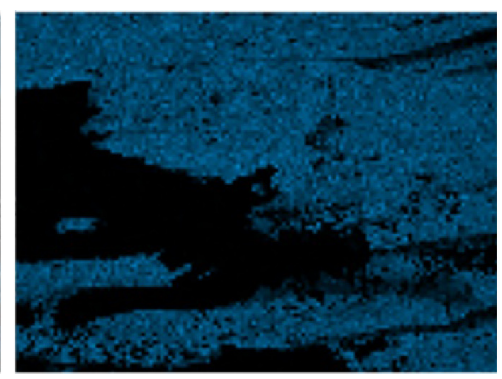

0

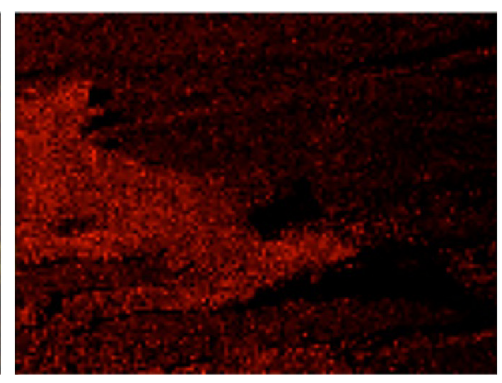

$\mathrm{Ca}$

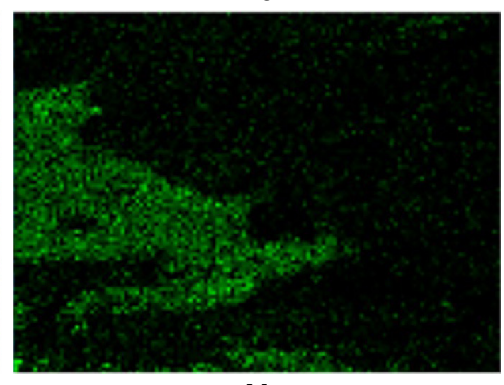

$\mathbf{N}$

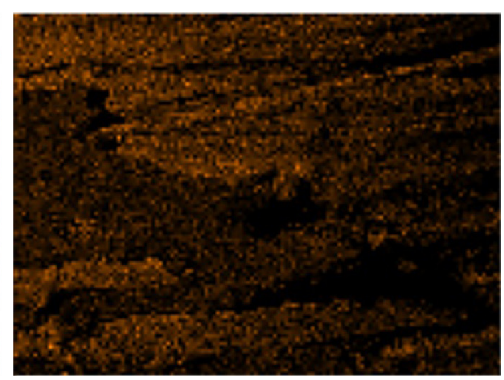

Figure 7 Scanning electron microscopy and EDS analyses of retrieved implants after 28 days.

Notes: The areas denoted by I and 2 are the sites for EDS analysis (A). The column graph (in $\mathbf{A}$ ) shows the relative concentrations of Ti, Ca, $\mathrm{P}, \mathrm{O}$, and $\mathrm{N}$ ( $\mathrm{n}=2-3$ ). In the column graph $(\mathbf{A})$ the plotted Ti concentration is 10 times reduced $(\mathrm{Ti} / \mathrm{I})$, while $\mathrm{Ca}$ and $\mathrm{P}$ concentrations are $\mathrm{I} 0$ times enhanced $(\mathrm{Ca} \times 10$ and $\mathrm{P} \times \mathrm{I0})$. The micrographs show the distribution of $\mathrm{Ti}, \mathrm{Ca}, \mathrm{P}, \mathrm{O}$, and $\mathrm{N}$ on a Nano surface (B).

Abbreviations: EDS, energy dispersive X-ray spectroscopy; Nano, nanopatterned.

the inflammatory cascade, including additional chemotactic factors, and by analysis of secreted protein at the nanotopography-tissue interface. The observation of higher recruitment of macrophages and a stronger inflammatory response at Ma surfaces corroborates earlier findings showing higher secretion and expression of TNF- $\alpha$, interleukin-1 beta (IL-1 ), and monocyte chemoattractant protein-1 (MCP-1) at $\mathrm{Ma}$ implants in comparison with oxidized surfaces, having a combined micron scale and nanoscale topography. ${ }^{12,14,28}$ Since a reduction of $T N F-\alpha$ and $I L-1 \beta$ has been demonstrated in association with oxidized surfaces, it is possible that the major reason for the attenuated inflammatory response with such surfaces was due to the nanocomponent. In fact, micron-scale topographies trigger the activation of macrophages in vitro, ${ }^{29}$ whereas the role of nanocues on macrophage activation has been less explored in vivo. The in vivo observation showing a reduced inflammatory response with $80 \mathrm{~nm}$ semispherical protrusions is in agreement with previous in vitro findings showing that nanotubes with similar size range $(70-80 \mathrm{~nm})$ reduce TNF- $\alpha$, IL-1 $\beta$, MCP-1, IL-6, and macrophage inflammatory protein 1-alpha (MIP-1 $\alpha$ ) in primary human monocytes/ macrophages and macrophage cell lines..$^{30-33}$ Interestingly, on the other hand, surfaces with similar nanoscale size range but with a groove shape were found to stimulate the expression/secretion of TNF- $\alpha$ and IL- $1 \beta$ in the murine macrophage RAW264.7 cell line in vitro. ${ }^{34}$ Taken together, it is apparent that both the size (micron versus nano) and the shape (eg, tubes versus grooves) are important determinants for macrophage activation. It cannot be excluded that even smaller sizes and other shapes of nanofeatures will further attenuate the inflammatory response. Interestingly, recent observations in vivo show that $30 \mathrm{~nm} \mathrm{TiO}_{2}$ nanotubes were associated with less inflammatory cell infiltration $\left(\mathrm{CD} 68^{+}\right.$ macrophages) compared to $80 \mathrm{~nm}$ nanotubes. ${ }^{35}$

An additional mechanism for the reduced inflammatory response can be related to the material surface adsorbed proteins and their conformational state as affected by the physicochemical properties of the nanotopography. Although this study did not explore the early (within hours) cell adhesion and protein content, it was evident, and not unexpected, that a protein matrix was observed on both surfaces at the earliest time point examined (3 days). While both immunostimulatory and immunosuppressive effects have been convincingly demonstrated for nanoparticles in suspension, ${ }^{36,37}$ few data exist for nanostructures when immobilized on surfaces. Interestingly, for example, only two studies have been published in the literature on the effect of nanotopography on complement activation. ${ }^{38,39}$ A link between biocompatibility and reduced thrombogenicity, at least partly related 
to an attenuated complement activation, has been suggested based on in vitro studies investigating the early interactions between plasma proteins and nanotextured surfaces. ${ }^{38,39}$

The observation of higher bone formation activities induced by the nanopattern, as judged by the higher early periostin staining and the late detection of $\mathrm{Ca}$ and $\mathrm{P}$, supports and extends previous histomorphometric findings at implants with similar chemistry, size, and shape of the nanofeatures. ${ }^{11}$ Further, the present observations using $80 \mathrm{~nm}$ hemispherical protrusions are in agreement with in vivo findings showing increased osteogenesis induced by implants with $70 \mathrm{~nm} \mathrm{TiO}_{2}$ nanotubes inserted in frontal skull bone of minipigs. ${ }^{40} \mathrm{In}$ contrast, no significant differences were detected for $A L P$, $O C$, or Runx 2 expression between Ma and Nano surfaces in this study. The exact reason for the discrepancy between the osteogenic gene expression and the present and the previous ${ }^{11}$ findings of enhanced mineralization by the nanopattern is unknown. This osteopromoting effect of the nanopattern might take place indirectly via the reduction of osteoclastic bone resorption, as indicated by the lower osteoclast gene expression of $\mathrm{Cat} K$ at the Nano implant. This assumption is supported by recent results showing that $\mathrm{CaP}$ materials doped with strontium, an osteoclastic inhibitor, induced a higher amount of bone formation than $\mathrm{CaP}$ materials. ${ }^{41,42}$ This was associated with a significant reduction of the osteoclastic gene expression of $C a t K$ and $C T R$, whereas the osteogenic gene expression of $A L P$ and $O C$ was not affected. ${ }^{41,42}$ Nevertheless, further evidence is required on the role of controlled nanotopography on the osteoclastic resorption, for instance by exploring the effect on the RANKL/RANK/OPG triad. Generally, few studies are available on the effect of nanotopography on osteoclasts, and contradictory findings to present observations have been reported showing that ceramics with less than $100 \mathrm{~nm}$ nanoscale grains and titanium implants with $70 \mathrm{~nm} \mathrm{TiO}_{2}$ nanotubes enhance the osteoclastic tartrateresistant acid phosphatase activity in vitro ${ }^{43}$ and in vivo, ${ }^{40}$ respectively. Taken together, the in vivo observations using controlled and well-defined nanotopography suggest that implant-adherent cells sense a specific range of nanotopography and transfer this information into a biological process, which results in increased bone formation and enhanced osseointegration.

The precise mechanism of enhanced osseointegration remains to be explored. Previous in vitro studies show that nanofeatures stimulate osteoblasts and their progenitors, including the osteogenic differentiation of MSCs. ${ }^{10,19-21,25,26,44-46}$ However, many of these studies use osteogenic differentiation media in the culture, and so the effect of nanotopography would be considered as an adjunctive effect. It is therefore interesting that in absence of differentiation media, surface nanotopography did neither induce differentiation nor lineage-specific gene expression changes of MSCs. ${ }^{47}$ This would imply that in the search for biological mechanisms of osseointegration induced by nanotopography, the full picture of bone formation and remodeling is dependent on several cell types and involves multiple biological processes, which are difficult to mimic during in vitro conditions.

In this study, after 28 days of healing, mature cortical bone could be seen covering the intramedullary part of both the Nano and the Ma implants. The elemental analysis using EDS showed a higher prevalence of $\mathrm{Ca}$ and $\mathrm{P}$ elements on the Nano surfaces. One interpretation for this observation is that mineralized tissue was more tightly bonded to the Nano surface, thereby withstanding the unscrewing procedure of the implant in bone better than the Ma implants. Support for this assumption is derived from observations of coalescence between the mineralized tissue and a nanostructured surface produced by laser ablation, resulting in an increased removal torque in vivo. ${ }^{48}$ Another interpretation is that the nanofeatures had promoted the mineralization process at the implant surface, similar to that found in vitro. ${ }^{49}$ These plausible explanations may coexist and need further exploration in vivo. In fact, both interpretations are in agreement with in vivo findings that the nanotopography of the implant surface induces a favorable bone response ${ }^{49-51}$ and promotes bone bonding. $6,7,27,48$

Most of the current understanding of cell interactions with well-defined nanotopography has been derived from in vitro studies using polymeric materials and, to a lesser extent, titanium. In this study, a well-defined nanopattern with predetermined shape, size, and density was successfully created on 3D titanium implants suitable for in vivo experimental studies. The technique produced a well-defined nanotopography with semispherical protrusions having uniform size $(80 \mathrm{~nm})$ and density $\left(31\right.$ hemisphere $/ \mu \mathrm{m}^{2}$ ), which together resulted in a $16 \%$ projected coverage of the surface and induced surface area by $34 \%$. The rationale behind the choice of this predetermined nanotopography was based on previous observations of a higher bone-to-implant contact with comparable size range (60 $\mathrm{nm}$ size; 36 hemisphere $/ \mu \mathrm{m}^{2}$ density) compared to two larger nanotopographies (120 nm size; 16 hemisphere $/ \mu \mathrm{m}^{2}$ density, and $220 \mathrm{~nm}$ size; 5 hemisphere/ $\mu \mathrm{m}^{2}$ density) and Ma implants. ${ }^{11}$ Therefore, this study was designed in order to elucidate the effect of such specific nanotopography on the cellular and molecular events of osseointegration. 
An apparent limitation of this study is the difficulty in directly translating the findings into clinical situations, since the present experimental implants do not resemble the conventional geometry of, for example, dental implants. In the current study, the installation site was drilled wider than the cylindrical part of the implants to ensure the preservation of the semispherical nanostructures. This is not the norm when preparing the recipient site for screw-shaped implants since primary stability is of utmost importance for osseointegration. Therefore, a logical next step would be refinements in methodology in order to apply the nanopatterns on clinically relevant, screw-shaped implants. Furthermore, with such implants, a primary stability in bone as well as a mechanical stability of the nanostructures needs to be assured.

\section{Conclusion}

This study describes the promotion of osseointegration with a controlled and well-defined nanotopography ( $80 \mathrm{~nm}$ semispherical protrusions) on titanium implants, produced by colloidal lithography. Using an experimental animal model in combination with cellular, molecular, and structural analytical techniques, it is demonstrated that the Nano implants elicit less influx of periimplant macrophages and downregulate the early expression of inflammatory and osteoclastic genes compared with clinically used Ma implants. Immunostaining and elemental analyses show higher osteogenic activity at the Nano implant. It can be concluded that implants with the present range of well-defined nanocues attenuate the inflammatory response while enhancing mineralization during osseointegration.

\section{Acknowledgments}

This study was supported by the BIOMATCELL VINN Excellence Center of Biomaterials and Cell Therapy, the Västra Götaland Region, the Swedish Research Council (K2015-52X-09495-28-4), LUA/ALF grant, optimization of osseointegration for treatment of transfemoral amputees (ALFGBG-448851), the Stiftelsen Handlanden Hjalmar Svensson, the Vilhelm and Martina Lundgren Vetenskapsfond, the IngaBritt and Arne Lundberg Foundation and the Area of Advance Materials of Chalmers and GU Biomaterials within the Strategic Research Area initiative launched by the Swedish Government.

\section{Author contributions}

DK assisted in experimental design, acquisition, analysis, and interpretation of data, and drafting and revising the article. $\mathrm{AB}$ participated in experimental design and performed experiments, data acquisition, and drafting the article. SP supported in experimental design, nanofabrication, surface analysis, data acquisition, drafting, and revising the article. HA participated in nanofabrication, surface and EDS analysis, data acquisition, and drafting the article. LE supported in experimental design and performed experiments and drafted the article. PT assisted in experimental design, data analysis and interpretation, and drafting, revising, and finalizing the article. OO performed experimental design and performed experiments, data analysis and interpretation, and drafting, revising, and finalizing the article. All authors approved the final manuscript and are accountable for all aspects of the work.

\section{Disclosure}

Part of the results of this study have been recently presented as a poster at the European Association for Osseointegration (EAO) Congress, Stockholm, Sweden 24-26 September 2015. The abstract of the poster was published in the official journal of the conference (Clin Oral Impl Res. 26 (Suppl 12), 2015). The authors report no other conflicts of interest in this work.

\section{References}

1. Branemark PI. Osseointegration and its experimental background. J Prosthet Dent. 1983;50(3):399-410.

2. Palmquist A, Omar OM, Esposito M, Lausmaa J, Thomsen P. Titanium oral implants: surface characteristics, interface biology and clinical outcome. J R Soc Interface. 2010;7(Suppl 5):S515-S527.

3. Davies JE, Mendes VC, Ko JC, Ajami E. Topographic scale-range synergy at the functional bone/implant interface. Biomaterials. 2014; 35(1):25-35.

4. Ellingsen JE, Thomsen P, Lyngstadaas SP. Advances in dental implant materials and tissue regeneration. Periodontol 2000. 2006;41:136-156.

5. Omar OM, Lenneras ME, Suska F, et al. The correlation between gene expression of proinflammatory markers and bone formation during osseointegration with titanium implants. Biomaterials. 2011; 32(2):374-386.

6. Branemark R, Emanuelsson L, Palmquist A, Thomsen P. Bone response to laser-induced micro- and nano-size titanium surface features. Nanomedicine. 2011;7(2):220-227.

7. Bjursten LM, Rasmusson L, Oh S, Smith GC, Brammer KS, Jin S. Titanium dioxide nanotubes enhance bone bonding in vivo. J Biomed Mater Res A. 2010;92(3):1218-1224.

8. Hanarp P, Sutherland D, Gold J, Kasemo B. Nanostructured model biomaterial surfaces prepared by colloidal lithography. Nanostruct Mater. 1999;12:429-432.

9. Hanarp P, Sutherland D, Gold J, Kasemo B. Control of nanoparticle film structure for colloidal lithography. Colloids Surf A Physicochem Eng Asp. 2003;214(1-3):23-36.

10. de Peppo GM, Agheli H, Karlsson C, et al. Osteogenic response of human mesenchymal stem cells to well-defined nanoscale topography in vitro. Int J Nanomedicine. 2014;9:2499-2515.

11. Ballo A, Agheli H, Lausmaa J, Thomsen P, Petronis S. Nanostructured model implants for in vivo studies: influence of well-defined nanotopography on de novo bone formation on titanium implants. Int J Nanomedicine. 2011;6:3415-3428.

12. Omar O, Lenneras M, Svensson S, et al. Integrin and chemokine receptor gene expression in implant-adherent cells during early osseointegration. J Mater Sci Mater Med. 2010;21(3):969-980. 
13. Omar O, Suska F, Lenneras M, et al. The influence of bone type on the gene expression in normal bone and at the bone-implant interface: experiments in animal model. Clin Implant Dent Relat Res. 2011; 13(2):146-156.

14. Omar O, Svensson S, Zoric N, et al. In vivo gene expression in response to anodically oxidized versus machined titanium implants. J Biomed Mater Res A. 2010;92(4):1552-1566.

15. Rozen S, Skaletsky H. Primer3 on the WWW for general users and for biologist programmers. Methods Mol Biol. 2000;132:365-386.

16. Vandesompele J, De Preter K, Pattyn F, et al. Accurate normalization of real-time quantitative RT-PCR data by geometric averaging of multiple internal control genes. Genome Biol. 2002;3(7):RESEARCH0034.

17. Andersen CL, Jensen JL, Orntoft TF. Normalization of real-time quantitative reverse transcription-PCR data: a model-based variance estimation approach to identify genes suited for normalization, applied to bladder and colon cancer data sets. Cancer Res. 2004;64(15):5245-5250.

18. Pfaffl MW. A new mathematical model for relative quantification in real-time RT-PCR. Nucleic Acids Res. 2001;29(9):e45.

19. de Oliveira PT, Nanci A. Nanotexturing of titanium-based surfaces upregulates expression of bone sialoprotein and osteopontin by cultured osteogenic cells. Biomaterials. 2004;25(3):403-413.

20. de Oliveira PT, Zalzal SF, Beloti MM, Rosa AL, Nanci A. Enhancement of in vitro osteogenesis on titanium by chemically produced nanotopography. J Biomed Mater Res A. 2007;80(3):554-564.

21. Ercan B, Webster TJ. Greater osteoblast proliferation on anodized nanotubular titanium upon electrical stimulation. Int J Nanomedicine. 2008;3(4):477-485.

22. Gao H, Li B, Zhao L, Jin Y. Influence of nanotopography on periodontal ligament stem cell functions and cell sheet based periodontal regeneration. Int J Nanomedicine. 2015;10:4009-4027.

23. Kulkarni M, Mazare A, Gongadze E, et al. Titanium nanostructures for biomedical applications. Nanotechnology. 2015;26(6):062002.

24. Shen X, Ma P, Hu Y, Xu G, Zhou J, Cai K. Mesenchymal stem cell growth behavior on micro/nano hierarchical surfaces of titanium substrates. Colloids Surf B Biointerfaces. 2015;127:221-232.

25. Vetrone F, Variola F, Tambasco de Oliveira P, et al. Nanoscale oxidative patterning of metallic surfaces to modulate cell activity and fate. Nano Lett. 2009;9(2):659-665.

26. Yao C, Slamovich EB, Webster TJ. Enhanced osteoblast functions on anodized titanium with nanotube-like structures. J Biomed Mater Res A. 2008;85(1):157-166.

27. Lenneras M, Palmquist A, Norlindh B, Emanuelsson L, Thomsen P, Omar O. Oxidized titanium implants enhance osseointegration via mechanisms involving RANK/RANKL/OPG regulation. Clin Implant Dent Relat Res. 2015;17(Suppl 2):e486-e500.

28. Omar OM, Graneli C, Ekstrom K, et al. The stimulation of an osteogenic response by classical monocyte activation. Biomaterials. 2011; 32(32):8190-8204.

29. Thomsen P, Gretzer C. Macrophage interactions with modified material surfaces. Curr Opin Solid State Mater Sci. 2001;5(2):163-176.

30. Ainslie KM, Tao SL, Popat KC, et al. In vitro inflammatory response of nanostructured titania, silicon oxide, and polycaprolactone. J Biomed Mater Res A. 2009;91(3):647-655.

31. Chamberlain L, Brammer K, Johnston G, Chien S, Jin S. Macrophage inflammatory response to $\mathrm{TiO}_{2}$ nanotube surfaces. J Biomater Nanobiotechnol. 2011;2(3):293-300.

32. Lu WL, Wang N, Gao P, Li CY, Zhao HS, Zhang ZT. Effects of anodic titanium dioxide nanotubes of different diameters on macrophage secretion and expression of cytokines and chemokines. Cell Prolif. 2015;48(1):95-104.

33. Neacsu P, Mazare A, Cimpean A, et al. Reduced inflammatory activity of RAW 264.7 macrophages on titania nanotube modified Ti surface. Int J Biochem Cell Biol. 2014;55:187-195.
34. Lamers E, Walboomers XF, Domanski M, et al. In vitro and in vivo evaluation of the inflammatory response to nanoscale grooved substrates. Nanomedicine. 2012;8(3):308-317.

35. Ma QL, Zhao LZ, Liu RR, et al. Improved implant osseointegration of a nanostructured titanium surface via mediation of macrophage polarization. Biomaterials. 2014;35(37):9853-9867.

36. Luo YH, Chang LW, Lin P. Metal-based nanoparticles and the immune system: activation, inflammation, and potential applications. Biomed Res Int. 2015;2015:143720.

37. Zolnik BS, Gonzalez-Fernandez A, Sadrieh N, Dobrovolskaia MA. Nanoparticles and the immune system. Endocrinology. 2010;151(2): $458-465$.

38. Hulander M, Lundgren A, Berglin M, Ohrlander M, Lausmaa J, Elwing $\mathrm{H}$. Immune complement activation is attenuated by surface nanotopography. Int J Nanomedicine. 2011;6:2653-2666.

39. Smith BS, Popat KC. Titania nanotube arrays as interfaces for bloodcontacting implantable devices: a study evaluating the nanotopographyassociated activation and expression of blood plasma components. J Biomed Nanotechnol. 2012;8(4):642-658.

40. Wang $\mathrm{N}, \mathrm{Li} \mathrm{H}, \mathrm{Lu} \mathrm{W}$, et al. Effects of $\mathrm{TiO}_{2}$ nanotubes with different diameters on gene expression and osseointegration of implants in minipigs. Biomaterials. 2011;32(29):6900-6911.

41. Cardemil C, Elgali I, Xia W, et al. Strontium-doped calcium phosphate and hydroxyapatite granules promote different inflammatory and bone remodelling responses in normal and ovariectomised rats. PLoS One. 2013;8(12):e84932.

42. Elgali I, Turri A, Xia W, et al. Guided bone regeneration using resorbable membrane and different bone substitutes: early histological and molecular events. Acta Biomater. 2016;29:409-423.

43. Webster TJ, Ergun C, Doremus RH, Siegel RW, Bizios R. Enhanced osteoclast-like cell functions on nanophase ceramics. Biomaterials. 2001;22(11):1327-1333.

44. Variola F, Vetrone F, Richert L, et al. Improving biocompatibility of implantable metals by nanoscale modification of surfaces: an overview of strategies, fabrication methods, and challenges. Small. 2009; 5(9):996-1006.

45. Lavenus S, Trichet V, Le Chevalier S, Hoornaert A, Louarn G, Layrolle P. Cell differentiation and osseointegration influenced by nanoscale anodized titanium surfaces. Nanomedicine (Lond). 2012 7(7):967-980.

46. Popat KC, Chatvanichkul KI, Barnes GL, Latempa TJ Jr, Grimes CA, Desai TA. Osteogenic differentiation of marrow stromal cells cultured on nanoporous alumina surfaces. J Biomed Mater Res A. 2007; 80(4):955-964.

47. Abagnale G, Steger M, Nguyen VH, et al. Surface topography enhances differentiation of mesenchymal stem cells towards osteogenic and adipogenic lineages. Biomaterials. 2015;61:316-326.

48. Palmquist A, Emanuelsson L, Branemark R, Thomsen P. Biomechanical, histological and ultrastructural analyses of laser micro- and nanostructured titanium implant after 6 months in rabbit. J Biomed Mater Res B Appl Biomater. 2011;97(2):289-298.

49. Mendonca G, Mendonca DB, Aragao FJ, Cooper LF. Advancing dental implant surface technology - from micron- to nanotopography. Biomaterials. 2008;29(28):3822-3835.

50. Orsini G, Piattelli M, Scarano A, et al. Randomized, controlled histologic and histomorphometric evaluation of implants with nanometerscale calcium phosphate added to the dual acid-etched surface in the human posterior maxilla. J Periodontol. 2007;78(2):209-218.

51. Meirelles L, Arvidsson A, Andersson M, Kjellin P, Albrektsson T, Wennerberg A. Nano hydroxyapatite structures influence early bone formation. J Biomed Mater Res A. 2008;87(2):299-307. 


\section{Publish your work in this journal}

The International Journal of Nanomedicine is an international, peerreviewed journal focusing on the application of nanotechnology in diagnostics, therapeutics, and drug delivery systems throughout the biomedical field. This journal is indexed on PubMed Central,

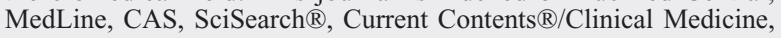

Journal Citation Reports/Science Edition, EMBase, Scopus and the Elsevier Bibliographic databases. The manuscript management system is completely online and includes a very quick and fair peer-review system, which is all easy to use. Visit http://www.dovepress.com/ testimonials.php to read real quotes from published authors.

Submit your manuscript here: http://www.dovepress.com/international-journal-of-nanomedicine-journal 